\title{
Orthodontists in forensic facial approximation (FFA): current inter-disciplinary perspective
}

\author{
Priyanka Kapoor ${ }^{{ }^{*}}$ (D), Aman Chowdhry ${ }^{2}$ a and Deepika Bablani Popli ${ }^{2}$ (i)
}

\begin{abstract}
Forensic odontology has contributed significantly in forensic investigations and involves various branches of dentistry including orthodontics. The current communication presents evidence-based perspective highlighting synergistic union of different specialties for Forensic Facial Approximation (FFA). It brings forth commonality in principles of anthropology, forensic science, anthropometry, anatomy, paleontology, forensic odontology, with orthodontics, used in FFA. Various attributes and skills of orthodontists' aid in dental and skull profiling and the corresponding sex, age, and ethnicity-based soft tissue assessments for facial soft tissue thickness (FSTT), may aid a life-like appearance. They can assist hard tissue profiling by their expertise in growth of skeletal and soft tissue, along with the evolutionary trends in occlusion, and diet formulations. Their knowledge in identifying teeth patterns, dental/skeletal jaw relationships, cranial/facial indices, vertical/horizontal facial proportions, can help prepare skull for orientation and reconstruction. The dental, photographic, and radiographic records maintained by orthodontists and general dentists are instrumental in data retrieval, used in various software, clinical, or research areas. These can provide normative values for comparative analysis or facial recreation. The orthodontists can also assist anthropologists and forensic specialists in the virtual reconstructions due to their ease in using latest digital technologies including three-dimensional (3D) facial scan, stereo-photogrammetry, 3D printing, automated soft-tissue landmarks, growth, and age predictions. Thus, the current study established the commonality in concepts of various forensic disciplines with orthodontics, which can strengthen both forensic on-field facial approximations and hard/soft tissue research to further enhance the accuracy of contemporary digital software used in FFA.
\end{abstract}

Keywords: Facial soft tissue thickness, Forensic facial reconstruction, Forensic facial approximation, Facial flatness indices, Orthodontics, Craniofacial anatomy, Dental, Skeletal jaw relationship

\section{Background}

Forensic facial approximation (FFA) is the art and science of reconstruction of a face to create a likeness to the face of the deceased, both for forensic and archeology purposes (Taylor 2000). It is a highly skilled procedure based on the sound scientific principles of osteology, physical anthropology, forensics, and art. The knowledge and

\footnotetext{
*Correspondence: pkapoor@jmi.ac.in

${ }^{1}$ Orthodontics \& Dentofacial Orthopaedics, Faculty of Dentistry, Jamia Millia Islamia, New Delhi 110025, India

Full list of author information is available at the end of the article
}

skills acquired during the dental undergraduate study curriculum can be pivotal in the final reconstruction of the face for use in forensics. Additionally, expertise attained in orthodontic post-graduation related to hard and soft tissue framework of the face can help reconstruct a more realistic face with their involvement and opinion during the reconstruction process.

Orthodontics as defined by Salzmann (1943) is "a branch of science and art of dentistry which deals with the developmental and positional anomalies of the teeth and the jaws as they affect oral health and the physical, esthetic and mental well-being of the person." (Singh 
2007). The specialty deals with the study of the craniofacial skeleton, diagnosis and treatment of craniofacial abnormalities, maxillo-mandibular relationships, dental mal-positioning, and longitudinal aspects of changes in hard/soft tissue with aging. Hence, the attributes which can make orthodontists an indispensable of the FFA team, have been discussed in this communication.

\section{Main text \\ Orthodontist in the FFA team: Science behind the art of facial approximation?}

Various aspects taught in dental undergraduate curriculum makes dentists suitable to be part of the FFA team. These are sound knowledge of anatomy and dental/skeletal relationships of jaws (in orthodontics), exposure to various software for photographs and radiographs, attaining manual dexterity and practical skills, knowledge of instruments and materials, helpful in FFA. (Chowdhry et al. 2018) The expertise is further enhanced in postgraduation (PG) where orthodontic PGs are taught craniofacial growth type and rotations, cephalometrics, standardized extra-oral/intra-oral photography, articulation of jaws and teeth along with the preservation of detailed records. This expertise can be useful in the profiling of skeletal and dental remains of an individual for comparative or reconstructive FFA to recreate its identity, as visually illustrated in the mindmaps by Kapoor et al. 2021.

Classic FFA technique involves 3 elements, viz. "anatomical modelling, determination of facial morphology, and finally facial reconstruction." (Wilkinson 2010). It establishes a multidisciplinary approach for FFA, involving branches of anatomy, biological or physical anthropology, and forensic science, where human craniofacial skeleton as well as soft tissue is studied from an evolutionary or growth perspective. The current communication highlights the commonality in principles employed in these branches working in FFA, with orthodontics. Thus, we propose that orthodontists in the FFA team could be of immense use in the following capacities:

1. Evolutionary trends

2. Reference planes on the skull

3. Dental profiling

3.1. Articulation of jaws and teeth

3.2. Measurements and morphologic characteristics of teeth

4. Skull and soft tissue profiling
4.1. Facial soft tissue thickness (FSTT)

4.2. Growth and age changes

4.3. Growth pattern/facial types

4.4. Nose prediction

4.5. Cephalic and facial indices

4.6. Facial symmetry and proportion

5. Ante-mortem records for comparison

6. Exposure to software and 3D facial imaging

Following communication elaborates on the various sub-heads under which orthodontists can contribute towards FFA, first highlighting their importance in FFA and then developing the interdisciplinary aspect of the particular sub-domain.

\section{Evolutionary trends Importance in FFA}

Various evolutionary prospects can be helpful in dental skull profiling during facial reconstruction and can improve chances of reconstructive identification. These include the growth of masticatory complex, age, caries status, ancestral oral milieu comprising of both biotic and abiotic components, third molar impaction, crowding, procumbence of upper incisors, abrasion, erosion status, etc. Besides, this information can also prove invaluable for identifying features and related musculature in skulls belonging to a different era while reconstructing them for museum models, ranging from prehistoric skulls to modern day collections. (Teja and Teja 2013; Moodie 1928)

\section{Interdisciplinary approach}

Orthodontic literature contributes immensely to evolutionary studies along with disciplines of anthropology, palaeontology, etc. They mostly study evolution of masticatory complex, its influence on the growth of cranial capacity and mandibular architecture. These parameters are directly influenced by the dietary transition from coarse rough diet to present-day civilized one. The regular components of orthodontic diagnosis can differentiate recent civilization from hunter-gatherers including evaluation of teeth, their relations to the craniofacial skeleton to upper and lower jaws, impactions, tooth size-jaw length discrepancy, tooth anomalies, etc. Thus, they can identify these features easily on the skull. (Teja and Teja 2013; Moodie 1928; Ungar et al. 2012)

\section{Reference planes on the skull Importance in FFA}

Orientation of skull on craniophore in natural head position (NHP), i.e., Frankfurt Horizontal Plane (FHP) 
parallel to the floor is mandatory for providing a standardized position of the skull before beginning FFA.

\section{Interdisciplinary approach}

The concept of skull reference planes originated in anthroposcopy and anthropometry where a gradual progression from earlier planes to FHP has been mentioned (Table 1, Fig. 1a-d) (Teja and Teja 2013). The extrapolation of NHP for skull orientation can be easily accomplished by orthodontists as they routinely use this position (Verma et al. 2012) while taking extra-oral photographs or lateral cephalogram radiographs. This concept of NHP is also taught in the undergraduate orthodontic practical training. Additionally, after tracing FHP on skull radiograph, relevant cephalometric analysis is performed. Hence, orthodontists are professionally trained to locate, orient and measure the skull in FHP.

\section{Dental profiling}

3.1 Articulation of jaws and teeth Importance in FFA

The knowledge of the skeletal arrangement of jaws (upper and lower) is essential to orient the mandible

Table 1 Evolution of reference planes (Teja and Teja 2013)

\begin{tabular}{lll}
\hline Year & Scientist name & Reference plane \\
\hline 1786 & Petrus Camper & $\begin{array}{l}\text { Nasal spine to center of auditory meatus } \\
\text { "Modern science of anthropometry" }\end{array}$ \\
1795 & Geoffroy de St. Hilaire & Auditory opening to free margin of incisor teeth \\
1862 & Broca & Alveolo-condylar plane-condyles to alveolar border of upper jaw "French horizontal" \\
1884 & International Anthropological & $\begin{array}{l}\text { From superior-most point of external auditory meatus (Porion) to most inferior point on bony Fig. 1d } \\
\text { orbit margin (Orbitale) }\end{array}$ \\
\hline
\end{tabular}

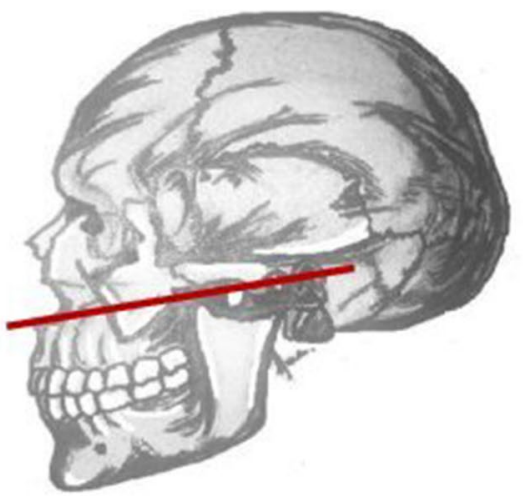

a:Petrus Camper Plane

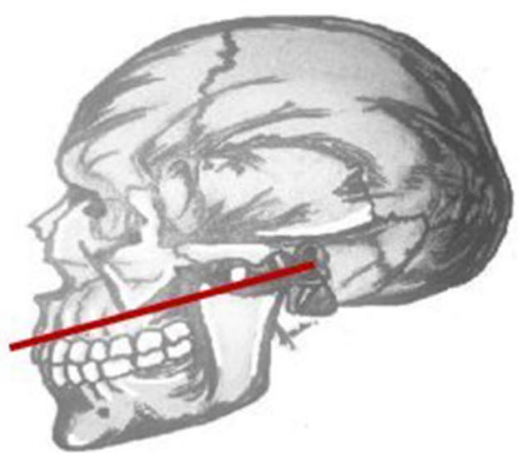

c: French Horizontal Plane

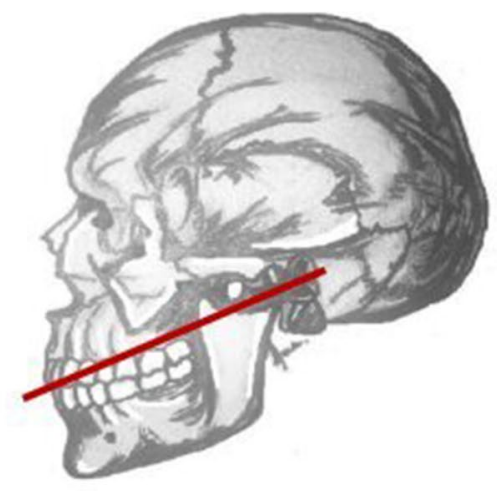

b: Geoffroy de St. Hilaire Plane

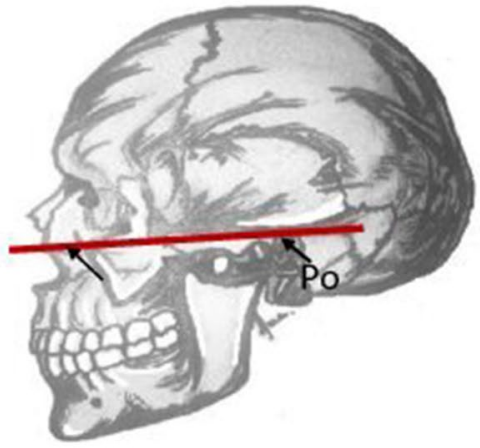

\section{d:Frankfurt Horizontal Plane}

Fig. 1 Reference planes for skull. a Petrus Camper plane. b Geoffroy de St. Hilaire plane. c French horizontal plane. d Frankfurt horizontal plane 
and skull exhibits retrieved from the crime site for FFA. This can also be used to finalize the arrangement of face types in the museum models belonging to a particular era. Besides, dental remains along with the fragmented portions of maxilla or mandible in mass disasters can be used for profiling sex, age, and ethnicity of individuals and finally help articulation of remains for reconstruction. Literature evidence also supports three-dimensional (3D) digital modeling, computer-aided design (CAD), and geometric morphometric thin-plate spline (TPS) methods for hemimandibular reconstructions (Benazzi et al. 2011), which is a common scenario requiring FFA. This also necessitates developing regression equations for calculation of dimensions of fragmented parts based on skull and cranium available.

\section{Interdisciplinary approach}

Orthodontists are trained to study the skeletal arrangement of jaws in following three basic arrangements, both clinically and on lateral cephalometric radiographs:

- Skeletal class I-Maxilla and mandible are normally arranged;

- Skeletal class II-Mandible is placed backward in relation to the maxilla;

- Skeletal class III-Mandible is forwardly placed than the maxilla.

Assessed majorly by ANB angle in Steiner's cephalometric analysis in multiple studies (Table 2, Fig. 2) (Chalala et al. 2019; Rana et al. 2012). The forensic odontologists, with a basic graduate dentistry background are also adept at identifying these skeletal arrangements, as the curriculum of BDS (Bachelor of Dental Surgery) includes practical as well as clinical exposure to these conditions. Additionally, dental students are trained to trace the landmarks and angular skeletal relations on cephalometry which gives them the skills to segregate skull and facial parameters
(Chowdhry et al. 2018). Other disciplines like physical anthropology measure facial flatness by slightly different terminologies (Table 3, Fig. 3a-c): frontal index, Simotic index, and Zygomaxillary index (Chalala et al. 2019). This difference in terminologies related to the same facial traits highlights the lacuna in uniformity in terminologies used by different disciplines. Uniformity will further ease communication amongst forensic anthropologists, orthodontists, physical anthropologists, and archeologists.

Alongside, the inter-arch dental relationships in orthodontics are classified as per Angle's classification based on occlusion of upper to lower first permanent molar. These are class I (normal), class II (post-normal), and class III (pre-normal) occlusion. Individual tooth mal-positions, like rotation, proclination, retroclination, and mesial/distal inclination, also act as an adjunct to dental profiling. These are also taught at dental undergraduate level on patients, study casts, and radiographs (Singh 2007). Hence, forensic odontologists with a basic dentistry background, along with orthodontists, are well versed with the terminologies and classifications of dental inter-relationships. They also have the professional expertise to communicate these parameters with the forensic specialists. Additionally, analyzing functional occlusion as canine guided or group function or balanced occlusion are concepts similar to the domain of gnathologists or physical anthropologists (Kaidonis et al. 2014) and works in establishing interrelationships of teeth in FFA. Orthodontic hard-tissue datasets may also be used to formulate regression equations for hemi-mandibular/ maxillary or cranial reconstructions.

\subsection{Measurements and morphologic characteristics of teeth Importance in FFA}

The odontometry and morphologic parameters of teeth can provide insight into age, sex, and ethnicity which

Table 2 Cephalometric points for sagittal and vertical skeletal jaw arrangement (Chalala et al. 2019; Rana et al. 2012)

\begin{tabular}{ll}
\hline Cephalometric point/angle & Explanation \\
\hline Point A (subspinale) & Deepest midline point in concavity from anterior nasal spine (ANS) to prosthion \\
Point B (supramentale) & Deepest midline point between infradental and pogonion. \\
Point Na (nasion) & Intersection of nasofrontal suture with internasal suture in mid-sagittal plane \\
ANB & Angle between the line subspinale to nasion and line joining nasion to supramentale \\
& Inference: \\
& $>4^{\circ}=$ skeletal class II relation \\
& $2^{\circ} \pm 2^{\circ}=$ skeletal class I relation \\
& $\leq 0^{\circ}=$ skeletal class III relation \\
Angle formed at intersection of mandibular plane (GO-Me) and sella-nasion (SN)
\end{tabular}




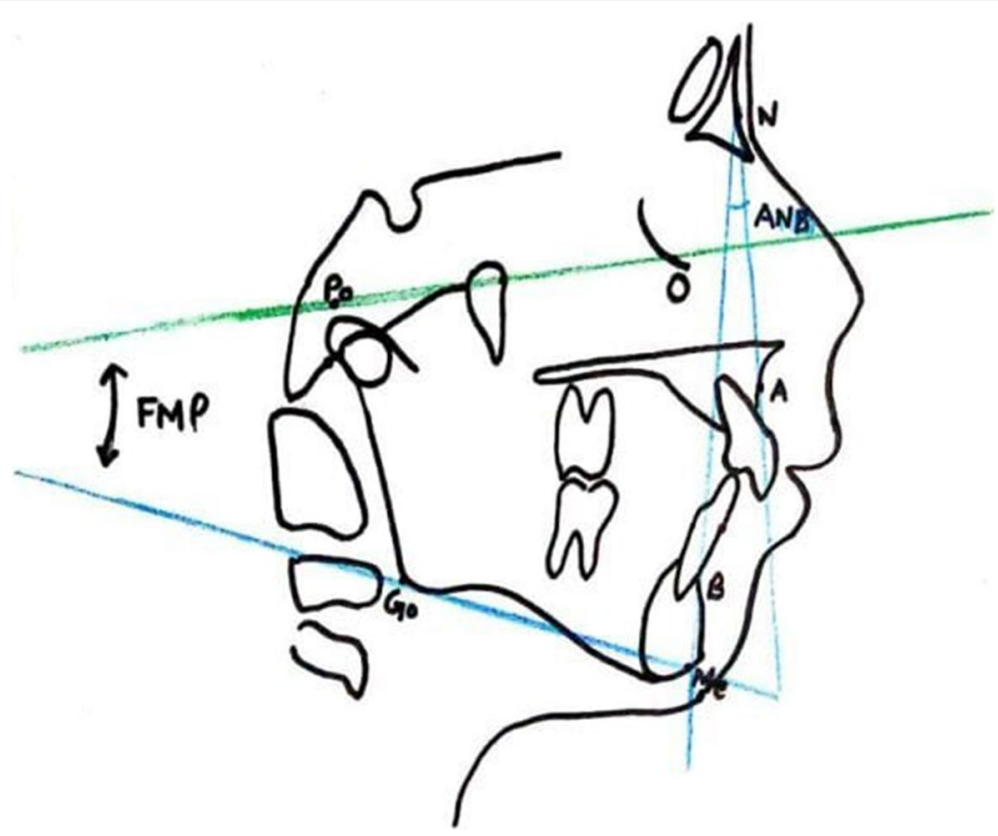

Fig. 2 Lateral cephalometric analysis, specifically ANB angle and FMP (Frankfurt mandibular plane)/MPA (mandibular plane angle)

can assist FFA in establishing identity of unknown skull.

\section{Interdisciplinary approach}

Anthropometry and tooth dimension/shape are studied by anatomists, anthropologists for identification and profiling. The metric traits are characteristically studied in orthodontics by clinical examination or study model analysis like Bolton's analysis or peck and peck ratio (Singh 2007). For the non- metric traits of variations in tooth morphology, various referencing systems have been proposed like widely used Arizona State University Dental Anthropology System (ASUDAS), which are be easily comprehended by orthodontists due to their basis of dental anatomy and morphology. The tooth morphology aspect is also taught very early to the dental undergraduates in their laboratory posting, theoretically as well as in tooth-carving exercises of dental anatomy. The students utilize their manual dexterity while carving each tooth and enhance their understanding of the morphological aspect of teeth. Slowly and steadily, the skills are honed clinically when they are applied in regular patient care. Hence, teeth profiling can be easily carried out by dental surgeons, forensic odontologists, and more intricately by the orthodontists. Besides, age and sex determination are conveniently based on clinical examination and radiographs by many established methods which are routinely studied and maintained in orthodontic records. (Kapoor 2018; Jasuja et al. 2018)

\section{Skull and soft tissue profiling 4.1 Facial soft tissue thickness (FSTT) Importance in FFA}

FSTT at the precise landmarks on the skull in facial reconstructions (Taylor 2000) gives a life-like face to the skull for identification. There are 21 soft tissue thickness landmarks, of which 10 are medial and 11 are lateral landmarks (Fig. 4a, b) (Taylor 2000; Kapoor 2018; Jasuja et al. 2018). Forensic specialists and artists working in the field of FFA require soft tissue data at these landmarks which are specific for sex, ethnicity, and age. These are used both for manual reconstructions and in data feed in

Table 3 Indices of facial flatness in anthropology (Chalala et al. 2019)

\begin{tabular}{ll}
\hline Index of facial flatness & Explanation \\
\hline Frontal index & Perpendicular distance of nasion from the frontal chord (2)/frontal chord (between the Frontomalaria Orbitalia) (1) \\
Simotic index & Minimum distance from the median ridge of nasal bone to simotic chord (3)/minimum horizontal breadth of nasal bone (4) \\
Zygomaxillary index & Distance from subspinale (point A) to zygomaxillary chord (6)/zygomaxillary chord ( between the zygomaxillaria anteriora) (5) \\
\hline
\end{tabular}


Table 4 Midline soft tissue landmarks for FSTT (Taylor 2000; Jasuja et al. 2018)

\begin{tabular}{lll}
\hline No. & \multicolumn{2}{l}{ Soft tissue midline Landmarks } \\
\cline { 2 - 3 } & Midline & Lateral \\
\hline 1 & SupraGlabella & Frontal eminence \\
2 & Glabella & Supraorbital \\
3 & Nasion & Lateral orbit \\
4 & End of Nasals & Suborbital \\
5 & Midphiltrum & Zygomatic arch midway \\
6 & Supradentale & Supraglenoid \\
7 & Infradentale & Inferior malar \\
8 & Supramentale & Supramolar \\
9 & Pogonion & Occlusal line \\
10 & Menton & Submolar \\
11 & & Gonion \\
\hline
\end{tabular}

automated 3D reconstructions. Different ethnic populations including Chinese, South Korean, Iranian, and Pakistani, have published soft tissue data specific to sex and age. But, only one study on north-west Indian origin on 173 males and 127 females has comprehensively studied FSTT in association body height, body weight, body mass index, tricep skin fold, and subscapular skin fold and also in comparison with other ethnicities (Sahni et al. 2008).

\section{Interdisciplinary approach}

Orthodontists routinely employ specific landmarks/ analysis on lateral cephalogram, CT (computed tomography), and $3 \mathrm{D}$ CBCT (cone beam $\mathrm{CT}$ ) to study their treatment effects and have also contributed tremendous literature related to FSTT in different classes of skeletal malocclusions (Kamak and Celikoglu 2012). The repeatability of central landmarks on lateral cephalograms has also been tested for inter and intra-observer repeatability (Bulut et al. 2016). Orthodontists can further study 21 landmarks of FFA to build vast soft-tissue data, specific for age, sex and ethnicity, and skeletal jaw relationships, which can significantly aid facial reconstructions.

\subsection{Growth and age changes Importance in FFA}

Growth of craniofacial skeleton, hard/soft tissue, and musculature are important variables when reconstructing the face of an unknown individual where approximate age and sex have to be ascertained.

\section{Interdisciplinary approach}

Orthodontist employs growth of the craniofacial skeleton, soft tissue, and changes in musculature to mold jaw abnormalities. Besides the use of employing growth in their clinical practice, they teach the growth of facial skeleton as part of BDS teaching. They make the dental graduates aware of the facial changes with growth and its effect on the clinical decision making. Classic longitudinal orthodontic studies have evaluated long term changes

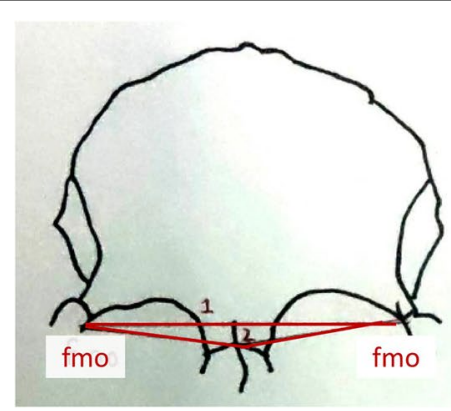

a:Frontal Index (2/1)
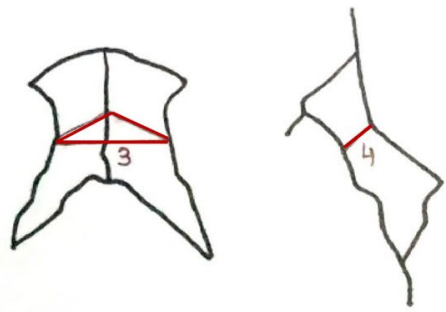

b:Simotic Index (3/4)

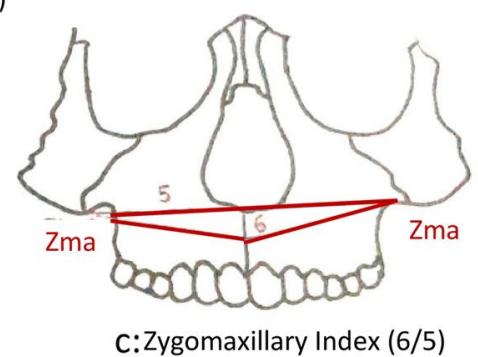

Fig. 3 Indices of facial flatness (Chalala et al. 2019). a Frontal index (2/1). b Simotic Index (3/4). c Zygomaxillary Index (6/5) 

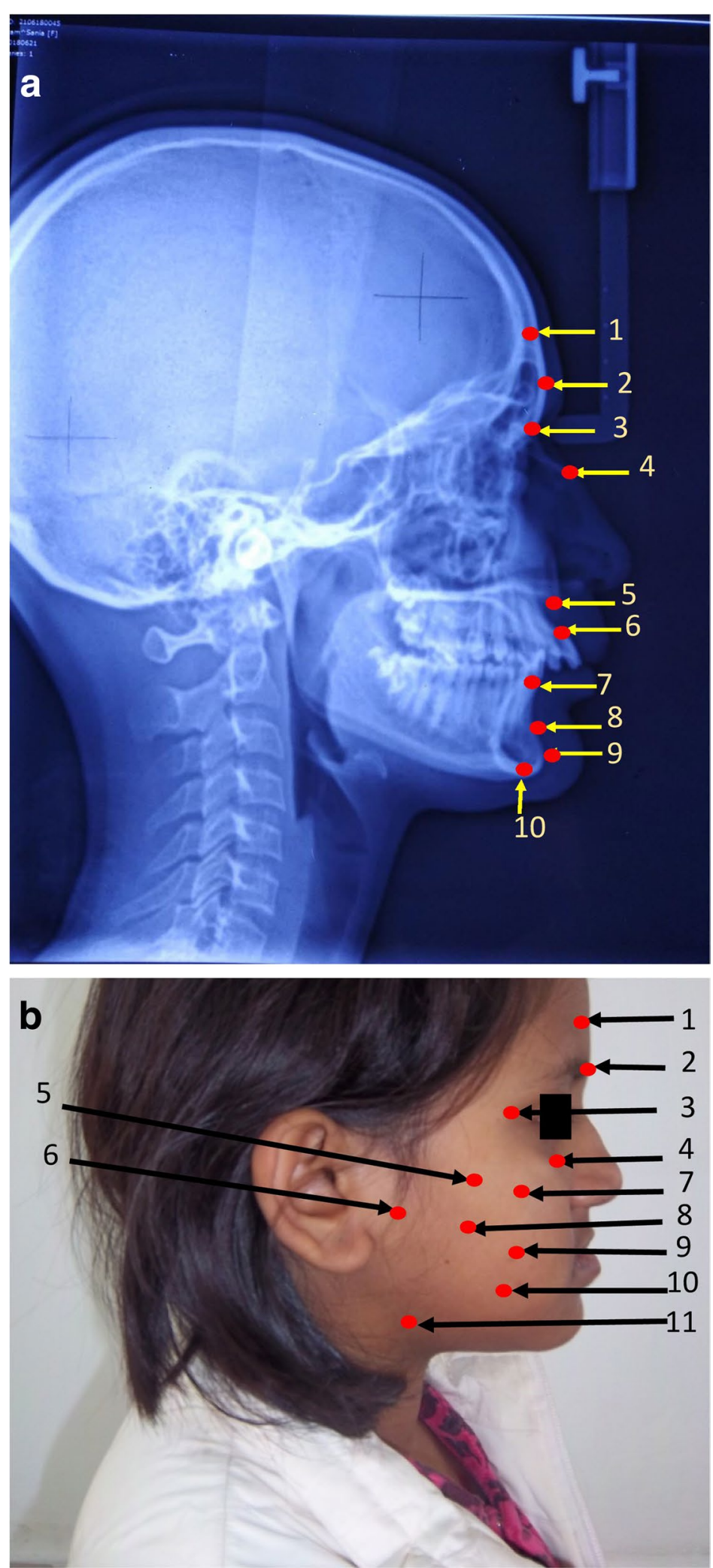

Fig. 4 Midline and lateral landmarks evaluated by orthodontists on lateral cephalograms and extra-oral photographs. a Representative lateral cephalogram showing midline landmarks for FSTT (Landmarks specified in Table 4). b Extrapolation of lateral skull landmarks on representative extra-oral photograph of patient (consent obtained for photograph) (landmarks specified in Table 4) 
in soft tissues of both males and females. These can provide data for age-specific changes in facial reconstructions (Foley and Mamandras 1992; Love et al. 1990; Riolo 1974). Other disciplines also represent similar human life stages but with different anthropologic classification. Bogin represents stages as 35-50 years: gradual decline, $>50$ years: degeneration/transition and senescence/old age (Bogin et al. 2018). The soft tissue changes at specific landmarks can be objectively studied with facial ageing/ stages. A recent study has created sex-specific trajectories of average facial aging by 3D modeling geometric morphometric analysis of 585 measurement points (landmarks and semi-landmarks) (Windhager et al. 2019). Similarly, orthodontists can also perform objective assessment of anthropologic stages of life at specific landmarks. This can be used to add research input to automated software programs of FFA employing age-related changes.

\subsection{Growth pattern/ facial types Importance in FFA}

The vertical relationship of the mandible to maxilla and cranium classifies the face into different facial types and is important while performing FFA. It can be influenced not only by age, sex, and ethnicity but also provide information about growth abnormalities, syndromes, or habits which can influence the facial reconstruction.

\section{Interdisciplinary approach}

Orthodontist routinely studies facial types determined by the growth pattern of adults nearing 18 years or in a range of 15-21 years, with mandibular plane angle (MPA) (Fig. 2). MPA can be measured both extra-orally and on lateral cephalograms. These variations are of interest to orthodontists, anthropologists, and anatomists, but orthodontic literature classifies these facial types objectively as follows: (Oh et al. 2019)

- Hyperdivergent $\left(\mathrm{MPA}>39^{\circ}\right)$,

- Norm-divergent $\left(28^{\circ} \leq \mathrm{MPA} \leq 39^{\circ}\right)$ and

- Hypo-divergent $\left(\mathrm{MPA}<28^{\circ}\right)$

These facial patterns are well taught at the dental undergraduate level so that forensic odontologists may hold expertise in identifying the growth pattern and assist the FFA team to reconstruct face based on underlying direction of growth of upper and lower jaws and their final arrangement.

A longitudinal Craniofacial Growth Consortium Study (CGCS) has measured MPA in 7026 lateral cephalograms of 728 individuals from ages 6 to 21 years and documented a decrease in MPA from childhood to adulthood, both in males $(92 \%)$ and females $(81 \%)$. But the only exception was hyper-divergent type, which documented an increase in angle in males (36\%) and females (50\%) (Hardin et al. 2020). Thus, in the reconstruction of the hyper-divergent face, these considerations may be important.

\subsection{Nose prediction Importance in FFA}

Prediction of nasal width, height, depth, tip, and other parameters are of significant importance to FFA as they are influenced by age, sex, and ethnicity. A study by Stephan $\mathrm{CN}$ et al, 2003 tested four methods for nose projection and position of pronasale-(I) Gerasimov 1971, (II) Krogman 1962, (III) Prokopec and Ubelaker 2002, (IV) George 1987. The first method used nasal spine and distal third of the nasal bones (Gerasimov 1971), the second one used average mid-philtrum soft-tissue depth and added it to three times nasal spine (Krogman 1962), third one used reflected profile line of nasal aperture (Prokopec and Ubelaker 2002), and the last one used the distance of Nasion to point A and a sex-dependent percentage of this distance was extrapolated on a line parallel to FHP on a point midway at anterior nasal spine (George 1987). Results of the study proved (Prokopec and Ubelaker 2002) and (George 1987) methods performed well for nose projection while the other two, though popular methods, proved inaccurate (Stephan et al. 2003). Similarly, other studies have focused on other parameters, like nasal index related to ethnic origins. A recent study on the Dayak tribe in Kalimantan, Indonesia, evaluating nasal index (nasal breadth/nasal height $\times 100$ ), proved that the most prominent nasal form is mesorrhine, followed by platyrrhine (Marini et al. 2020)

\section{Interdisciplinary approach}

Orthodontists give maxillary expansion devices in normal or cleft lip and palate (CLP) patients which cause changes in the nasal base and width. There is extensive orthodontic literature related to nasal morphology, width, and depth on lateral cephalograms and lately on 3D stereophotogrammetry, specific to sex, age, and skeletal classifications (Umale et al. 2017). Other studies have also proved a significant association of nasal morphology (nasal height, depth, bone length, nasal tip angle, nasolabial angle, and upper lip inclination angle) to the maxillary inclination (Bhushan et al. 2015). Thus, orthodontists can aid forensic specialists to generate research related to nasal morphology for FFA, also altered by vertical and sagittal maxillary growth. 


\subsection{Cephalic and facial indices Importance in FFA}

Measurements of face and cranium vary with different ethnic origins and age, and are of prime importance while recreating a face of unknown ethnic origin or to create the right proportions in identified museum models. A comprehensive database has been formed by studying 18-30 years old 1470 healthy subjects from multiple origins-Asian, European, Middle East, and African continents (Farkas et al. 2005). There are various computer programs like FORDISC, CRANID, and ANCESTREES which can decipher the ancestry of unknown crania based on pre-fed values to various craniometric parameters (Saini et al. 2017). Each of the programs has datasets from the collection of crania of different populations but Indian populations still do not have much representation due to their lack of skeletal assemblage owing to religious constraints or cremation issues. A study undertaken on 483 adult crania from Uttar Pradesh, India, reported the secular and sex-related changes on cranial measurements, and also classified the North India crania based on various indices; the cranial index is one of them (Saini et al. 2017). Other Indian studies have also attempted study of facial indices with respect to sex or ethnicity (Franco et al. 2013).

\section{Interdisciplinary approach}

Orthodontist usually studies these face and cranium measurements on live individuals as facial and cephalic indices (Fig. 5a, b, Table 5) (Franco et al. 2013; Kolar and Salter 1997; Deniker 2012).

$$
\begin{aligned}
& \text { Cephalic Index (on live individuals) }=\frac{\text { Maximum head width }}{\text { Maximum head length }} \times 100 \\
& \text { Facial Index }=\frac{\text { Maximum face length (Nasion to Gnathion) }}{\text { Maximum face width (Bizygomatic width) }} \times 100
\end{aligned}
$$

Correspondingly, the cephalic index corresponds to the cranial index assessed on cadavers' in craniometry. Few Indian studies have attempted study of facial indices with respect to sex or ethnicity (Missier et al. 2018). These basic indices are part of extra-oral examination in dental undergraduate history-taking process; hence,

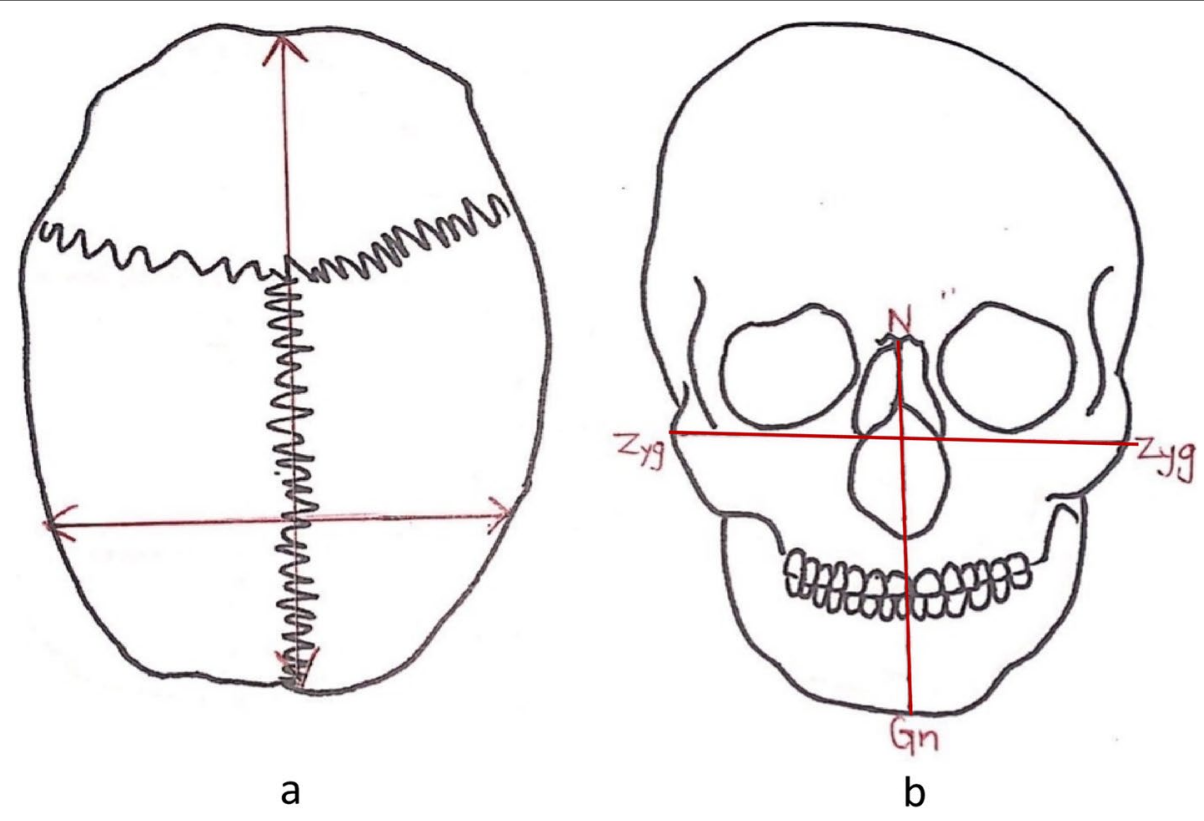

Fig. 5 Cephalic and facial index (Franco et al. 2013). a Maximum skull width/ length. b Nasion-Gnathion/ Bizygomatic width

Table 5 Types of cephalic and facial index with inference (Wilkinson 2010; Franco et al. 2013)

\begin{tabular}{lllllll}
\hline Cephalic index & Anthropologic terms & Value & Inference & Facial index & Value & Inference \\
\hline Dolichocephalic & Hypsicephalic & $70.0-74.9$ & Long and narrow cranium & Leptoprosopic & $90.0-94.9$ & Long and narrow face \\
Mesocephalic & Orthocephalic & $75.0-79.9$ & Average cranium & Mesoprosopic & $85.0-89.9$ & Average face \\
Brachycephalic & Platycephalic & $80.0-84.9$ & Broad and short cranium & Euryprosopic & $80.0-84.9$ & Broad and short face \\
\hline
\end{tabular}


the forensic odontologists in the FFA team may provide technical skills for measurement along with research data inputs for these cranial parameters.

Orthodontists can conveniently extend their domain by measuring these indices for facial attractiveness, establishing a balanced face, and formulating ethnicity-specific comprehensive databases for automated facial reconstruction by means of suitable software.

\subsection{Facial symmetry and proportion Importance in FFA}

Facial proportions are the key to creating a balanced face when one of the parameters, either face height or width may be known to the forensic specialist recreating face. Forensic specialists have used varied parameters for prediction of facial height and proportions, like dermatoglyphics or ridge patterns on thumb or fingers, primarily because fingerprints are most commonly used and easily available for identification. One of the studies have evaluated thumbprints of 457 males and female from the Hausa population, and revealed significant predictive variables for face heights and face widths. Right, ulnar ridge count established prediction of lower facial width (LFW), the ratio of upper face width (UFW)/LFW, UFW/UFH (upper face height), LFH (Lower face height)/ FH (Face height) in males, and UFH in females (Adamu et al. 2017a, b). Another study on the same population used ridge count to predict nasolabial distance. Left proximal ridge count was found to correlate negatively with the length of the nose, philtrum, upper lip, and width of mouth in males while it correlated positively with lower vermilion width in females (Adamu et al. 2017a, b).

\section{Interdisciplinary approach}

Orthodontist studies the symmetry and proportions of face for each of their patients. The bilateral symmetry of face (Premkumar 2015) is judged by the comparison of right and left sides of the face with respect to the midsagittal plane. The transverse proportion is studied by Rule of 5 (Fig. 6):

- A-A' width of the base of nose = Inter-canthal distance

- Width of mouth $=$ Approximate distance between irises (B-B')

- Central (A-A"), Medial (A-C, A'-C'), and lateral (C-D, $C^{\prime}$-D') fifths are equal in a proportioned face.

The vertical proportions are studied separately for the lower third and full-face: (Fig. 7)

The lower third of face: Subnasale-Stomium $=1 / 3 \mathrm{rd}$, Stomiom-Menton $=2 / 3$ rd

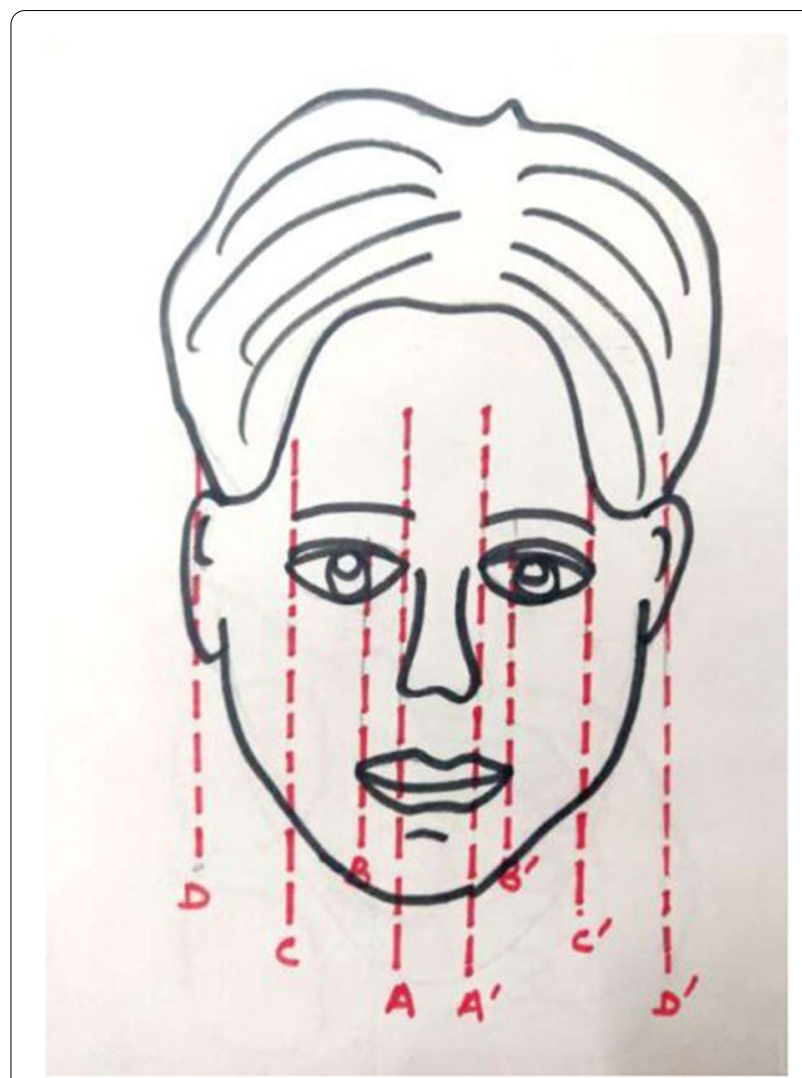

Fig. 6 Measure for transverse symmetry Rule of $5=$ central $\left(A-A^{\prime \prime}\right)$, medial $\left(A-C, A^{\prime}-C^{\prime}\right)$, and lateral $\left(C-D, C^{\prime}-D^{\prime}\right)$ fifths are equal in a proportioned face (Premkumar 2015)

Full face vertical proportions: hairline-eyebrows: $1 / 3 \mathrm{rd}$, eyebrows-base of the nose: $1 / 3 \mathrm{rd}$, base of nose-chin: $1 / 3$ rd.

The vertical and horizontal facial proportions are taught as a part of dental under-graduate curriculum and are also studied in anthropometry by "neoclassical canons" for a harmoniously balanced face. This concept was evaluated by Farkas on a sample of 153 North American Caucasians, 6-, 12-, and 18-year-olds. They tested the validity of nine neoclassical formulas of facial proportions and also age-related qualities. The results showed the highest validity of only two horizontal canons in young adults-interorbital width $=$ nose width (in $40 \%$ ), nose width $=1 / 4$ face width (in $37 \%$ ) but vertical profile proportions showed weak correspondence (L. G. Farkas et al. 1985). These anthropologic facial proportions can also be studied in orthodontic patients for prediction of face heights and widths. Further new dimensions in facial characterization can be explored by correlating with dermatoglyphics or ridge count/number which can be used in forensic reconstruction, paleo-demography, and orthodontics. 


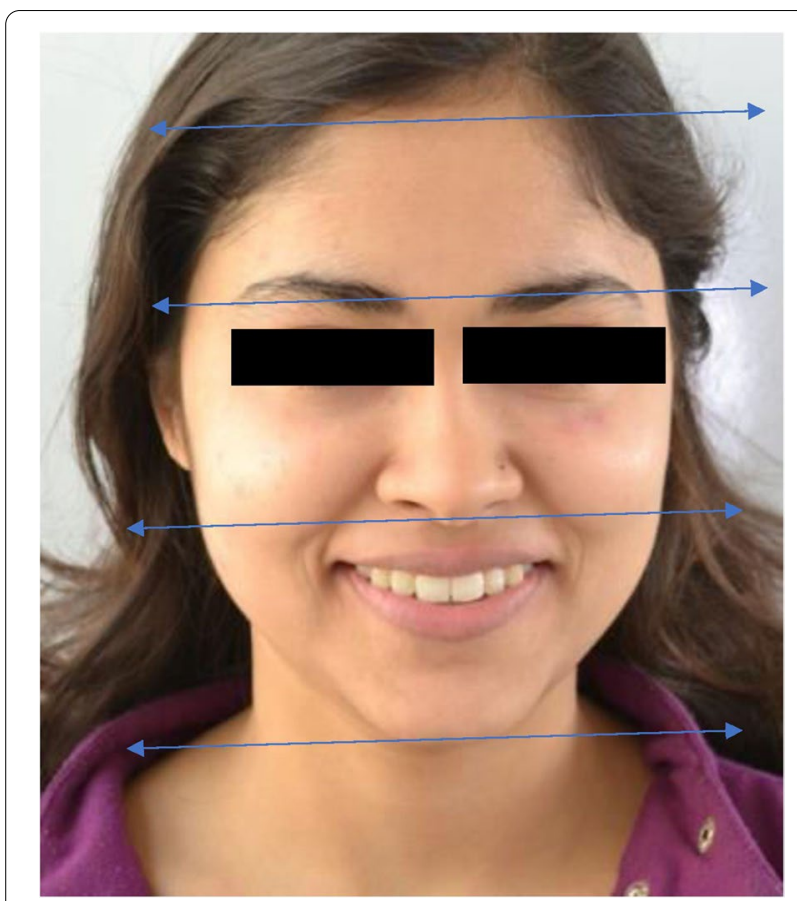

Fig. 7 Vertical proportions: hairline to eyebrows, eyebrow-base of nose, base of nose-chin should be equal for balanced face (Premkumar 2015)

\section{Ante mortem data bank for comparison Importance in FFA}

In airplane crashes or conditions where ante mortem data can be made available for comparative identification of deceased, the photographic and radiographic antemortem records play an important role in forensic facial reconstructions (Sarode et al. 2017).

\section{Interdisciplinary approach}

Of all the branches of dentistry, orthodontics is known to perform detailed record-keeping, preferably stagewise for all patients over an extended treatment time of approximately two years, with a follow up of at least 5 years. The records include case history, photographs, and radiographs, which can serve as valuable ante-mortem records for FFA (Kapoor et al. 2021; Kapoor 2018). Case history sheet mentions patient demographics, history (dental, medical, family history), and dental occlusion characteristics along with treatment progress. Photographs comprise of a standard set of 5 intra-oral (right lateral, left lateral, frontal, maxillary occlusal, and mandibular occlusal) and 3 extra-oral (frontal, profile, $45^{\circ}$ ) photographs, which can be stored digitally to evaluate the occlusal relationships as well as peculiar characteristics (like attrition and fractures). Additionally, study casts, in physical form or 3D digital models can be used to evaluate the malocclusions, rugae pattern, and genetic preponderance for certain dental features. Radiographs comprise of the essential set of lateral cephalograms and orthopantomograms, which can be used to evaluate the bony and dental parameters along with growth status (Kapoor et al. 2021). General dentists, in addition, at every level maintain some level of dental record system and may prove useful for the forensic team while reconstruction or may also be used for population-specific research data inputs.

\section{Exposure to softwares and 3D facial imaging Importance in FFA}

3D reconstructions involve newer advents in FFA technologies like touchscreens (e.g., Cintiq ${ }^{\circledR}$ pen displays by WACOM $^{\circledR}$ ) or haptic feedback devices (such as Geomagic ${ }^{\circledR}$ TouchTM by 3D SYSTEMS ${ }^{\circledR}$ ) (Guyomarc'h et al. 2014) which require the forensic artist to be comfortable with the latest software. Normally, for reconstruction, 3D facial scans of the skull are taken, to be transferred as a digital file for 3D printing used to create skull analog for manual reconstruction. Some computerized reconstructions also use the DICOM (Digital Imaging and Communications in Medicine) data or file scan for automated location of 3D landmarks for independent estimation of FSTT and the facial shape is attained through geometric morphometrics (Guyomarc'h et al. 2014). An automatic forensic facial reconstruction method has been proposed using FSTT data statistics derived from computed tomography (CT) head and optical scans (Gietzen et al. 2019). This data has been applied to the volumetric (skull model which encodes different skull variations. A skull obtained from the CT source is then matched for template skulls generating spheres with a radius of associated values for FSTT value from statistic each skull vertices. It helps to generate possible head variants with the feasibility of adjustment using principal component analysis (Guyomarc'h et al. 2014)

\section{Interdisciplinary approach}

Latest advents of digitization in orthodontics can potentiate each step of computerized FFA, right from acquisition of face shape by 3-D scan technology (e.g., 3dMDface System ${ }^{\circledR}$ by $3 \mathrm{dMD}^{\circledR}$, Space Spider $^{\circledR}$ by Artec ${ }^{\circledR}$ ) to application of generalized trends of soft tissue as per ethnic populations (Gietzen et al. 2019). Additionally, changes in FSTT with age and collaboration with the hard/soft tissue data sets obtained from CBCT)/CT which can be easily transferred via DICOM data are routinely performed by orthodontists, which can be the primary armamentarium for computerized FFA. Orthodontists often use automated virtual simulation software (NemocephTM, OnyxCeph 3TM, etc.) for treatment planning, 
execution, and patient education, hence their adaptability is high while working on the latest FFA technologies. Orthodontists can also generate FSTT data statistics for automated FFA using CT/CBCT or optical scans.

The critical review of the current literature has brought forth the following issues which may be considered in the future:

1. The orthodontists may be a part of the FFA team due to the commonality in principles of anthropology, anthropometry, craniometry, forensic science, and orthodontics.

2. A universal terminology should be devised for communication amongst researchers of different disciplines, related to common concepts of reference planes, growth patterns, facial types, vertical and horizontal proportions, and facial and cranial indices.

3. A common research data or pool is required for FSTT data or hard/soft tissue data of different ethnic variants, which may be used for contribution to automated FFA software.

\section{Conclusions}

a. Orthodontists can assist FFA team in multiple capacities, including dental, skull, and soft tissue profiling to ascertain age, sex, and ethnicity of skull in reconstructive identification or facial approximation.

b. Their knowledge and expertise in skull orientation relative to specific reference planes, along with horizontal and vertical facial proportions, nasal predictions, cephalic, and facial indices, establishes their role in tandem with anthropology, anatomy, and forensic disciplines for determining the skeletal structure for FFA.

c. The assessment of growth and age changes routinely done by orthodontists can help FFA team determine the orientation of mandibular planes well as soft tissue thickness changes with age.

d. The photographic, study cast, and radiographic antemortem records maintained by orthodontists or general dentists can serve invaluable for comparative evaluation as well as in providing raw data for future research to be used in ethnicity-/age-/sex-based reconstruction software.

e. Their exposure to 3D facial imaging and software can come handy in generating data or using it for morphometric comparisons, face pool assessment, and resemblance ratings (Wilkinson 2010). It can also in future enhance the accuracy of virtual reconstructions based on sound scientific data.

\section{Abbreviations}

3D: Three-dimensional; ASUDAS: Arizona State University Dental Anthropology System; CAD: Computer-aided design; CBCT: Cone beam computed tomography; CLP: Cleft lip and palate; CT: Computed tomography; DICOM: Digital Imaging and Communications in Medicine; FFA: Forensic facial approximation; FH: Face height; FHP: Frankfurt horizontal plane; FSTT: Facial soft tissue thickness; LFH: Lower face height; MPA: Mandibular plane angle; NHP: Natural head position; TPS: Thin-plate spline; UFH: Upper face height; UFW: Upper face width.

\section{Acknowledgements}

We extend special thanks to Dr. Vineeta Saini, Assistant Professor, Department of Forensic Science, SGT University, for critical valuable inputs in the manuscript. Also, heartiest thanks to Dr. Lubna Ahmad, Intern, for the help with the images.

\section{Authors' contributions}

PK has made substantial contributions to the conception and design of the work; drafted the work or substantively revised it and approved the submitted version. AC has made substantial contributions to draft of work or substantively revised it, and approved the submitted version. DBP has made substantial contributions to draft of work or substantively revised it and approved the submitted version. All authors have read and approved the manuscript.

\section{Funding}

None to declare.

Availability of data and materials

Not applicable.

\section{Declarations}

Ethics approval and consent to participate

Not applicable.

\section{Consent for publication}

Written informed consent to publish patient photos and radiographs was obtained from study participant and/or his/her parent/legal guardian.

\section{Competing interests}

The authors declare that they have no competing interests.

\section{Author details}

${ }^{1}$ Orthodontics \& Dentofacial Orthopaedics, Faculty of Dentistry, Jamia Millia Islamia, New Delhi 110025, India. ${ }^{2}$ Oral Pathology \& Microbiology, Faculty of Dentistry, Jamia Millia Islamia, New Delhi 110025, India.

Received: 16 August 2021 Accepted: 1 November 2021

Published online: 20 November 2021

\section{References}

Adamu LH, Ojo SA, Danborno B, Adebisi SS, Taura MG (2017b) Prediction of facial height, width, and ratio from thumbprints ridge count and its possible applications, vol 3, pp 223-228

Adamu LH, Ojo SA, Danborno B, Adebisi SS, Taura MG (2017a) Prediction of nasolabial distance using thumbprint ridge density among the Hausa population of Nigeria. Arab J Forensic Sci Forensic Med 1(5) https://doi. org/10.26735/16586794.2017.021

Benazzi S, Fiorenza L, Kozakowski S, Kullmer O (2011) Comparing 3D virtual methods for hemimandibular body reconstruction. Anat Record (Hoboken, N.J.: 2007) 294(7):1116-1125 https://doi.org/10.1002/ar.21410

Bhushan R, Kumar S, Chauhan AK, Mohan S, Shekhar M, Narnoly A (2015) Assessment of the relationship between maxillary rotation and nasal morphology 
in males. Contemp Clin Dent 6(Suppl 1):S12-S17 https://doi.org/10.4103/ 0976-237X.152931

Bogin, Barry, Carlos Varea, Michael Hermanussen, and Christiane Scheffler. (2018). Human life course biology: a centennial perspective of scholarship on the human pattern of physical growth and its place in human biocultural evolution. Am J Phys Anthropol 165 (4): 834-854. https://doi.org/https://doi.org/ 10.1002/ajpa.23357.

Bulut O, Kahraman G, Nicolle T, Hizliol I, Gurcan S, Hekimoglu B, Kaya E, Ozdede M, Akay $G$ (2016) Repeatability of facial soft tissue thickness measurements for forensic facial reconstruction using X-ray images. 49(2):108

Chalala C, Saadeh M, Ayoub F (2019) Facial flatness indices: application in orthodontics. PeerJ 7(May):e6889. https://doi.org/10.7717/peerj.6889

Chowdhry, Aman, Priya Kapoor, D. Popli, K. Sircar, and Ragini Miglani. (2018). Inclusion of forensic odontologist in team of forensic facial approximationa proposal and technical note. https://doi.org/10.7860/jcdr/2018/35863. 12003.

Deniker J (2012) The races of man: an outline of anthropology and ethnography. Nabu Publication, London

Farkas LG, Hreczko TA, Kolar JC, Munro IR (1985) Vertical and horizontal proportions of the face in young adult North American Caucasians: revision of neoclassical canons. Plast Reconstr Surg 75(3):328-338. https://doi.org/10. 1097/00006534-198503000-00005

Farkas LG, Katic MJ, Forrest CR, Alt KW, Bagic I, Baltadjiev G, Cunha E et al (2005) International anthropometric study of facial morphology in various ethnic groups/races. J Craniofac Surg 16(4):615-646. https://doi.org/10.1097/01.scs. $0000171847.58031 .9 \mathrm{e}$

Foley TF, Mamandras AH (1992) Facial growth in females 14 to 20 years of age. Am J Orthod Dentofacial Orthop 101(3):248-254. https://doi.org/10.1016/ 0889-5406(92)70094-Q

Franco FC, Menezes TM, de Araujo C, Vogel J, Quintão CCA (2013) Brachycephalic, dolichocephalic and mesocephalic: is it appropriate to describe the face using skull patterns? Dent Press J Orthod 18(June):159-163. https://doi.org/ 10.1590/S2176-94512013000300025

George, R. M. (1987). "The Lateral Craniographic Method of Facial Reconstruction." https://doi.org/10.1520/JFS11181J.

Gerasimov M (1971) The Face Flnder. Hutchinson \& Co, London

Gietzen T, Brylka R, Achenbach J, Hebel K z, Schömer E, Botsch M, Schwanecke U, Schulze R (2019) A method for automatic forensic facial reconstruction based on dense statistics of soft tissue thickness. PLoS One 14(1):e0210257. https://doi.org/10.1371/journal.pone.0210257

Guyomarc'h P, Dutailly B, Charton J, Santos F, Desbarats P, Coqueugniot H (2014) Anthropological facial approximation in three dimensions (AFA3D): computer-assisted estimation of the facial morphology using geometric morphometrics. J Forensic Sci 59(6):1502-1516. https://doi.org/10.1111/ 1556-4029.12547

Hardin AM, Valiathan M, Heesoo O, Knigge RP, McNulty KP, Leary EV, Duren DL, Sherwood RJ (2020) Clinical implications of age-related change of the mandibular plane angle. Orthodon Craniofac Res 23(1):50-58. https://doi. org/10.1111/ocr.12342

Jasuja OP, Chowdhry A, Kapoor P (2018) Forensic facial reconstruction: role of dentist. In: Handbook of Forensic of Forensic Odontology: An Indian Perspective, 1st edn. Century Publications, India, pp 126-133

Kaidonis JA, Ranjitkar S, Lekkas D, Brook AH, Townsend GC (2014) Functional dental occlusion: an anthropological perspective and implications for practice. Aust Dent J 59(Suppl 1 (June)):162-173. https://doi.org/10.1111/adj.12133

Kamak H, Celikoglu M (2012) Facial soft tissue thickness among skeletal malocclusions: is there a difference? Korean J Orthod 42(1):23-31. https://doi.org/ 10.4041/kjod.2012.42.1.23

Kapoor P (2018) Role of orthodontics in forensic odontology. In: Handbook on Forensic Odontology: An Indian Perspective, 1st edn. Century Publications, India, pp 144-150

Kapoor P, Chowdhry A, Chaudhry A (2021) Using mind maps to understand the role of orthodontists in forensic odontology: an illustrative review. J Indo Pac Acad Forensic Odontolgoy 10(1):25-32

Kolar JC, Salter EM (1997) Craniofacial anthropometry: practical measurement of the head and face for clinical, surgical, and research use. C.C. Thomas, Springfield

Krogman WM (1962) The human skeleton in forensic medicine. Charles C. Thomas, Springfield

Love RJ, Murray JM, Mamandras AH (1990) Facial growth in males 16 to 20 years of age. Am J Orthod Dentofacial Orthop 97(3):200-206. https://doi.org/10. 1016/S0889-5406(05)80052-6
Marini, Maria Istiqomah, Hastomo Angrosidy, Arofi Kurniawan, and Mieke Sylvia Margaretha. (2020). The anthropological analysis of the nasal morphology of Dayak Kenyah population in Indonesia as a basic data for forensic identification. Transl Res Anat 19 (June): 100064. https://doi.org/https://doi.org/10. 1016/j.tria.2020.100064.

Missier MS, Samuel SG, George AM (2018) Facial indices in lateral cephalogram for sex prediction in Chennai population - a semi-novel study. J Forensic Dent Sci 10(3):151-157. https://doi.org/10.4103/ffo.jfds_81_18

Moodie, RL. (1928). Studies in Paleodontology. I. Materials for a Study of Prehistoric Dentistry in Peru**Work Done under Grants from the Research Commission of the American Dental Association and the University of Southern California, College of Dentistry. | Moodie, Roy L. | Download." https://doi.org/ 10.14219/jada.archive.1928.0330.

Oh H, Knigge R, Hardin A, Sherwood R, Duren D, Valiathan M, Leary E, McNulty K (2019) Predicting Adult Facial Type from Mandibular Landmark Data at Young Ages. Orthod Craniofac Res 22(Suppl 1 (May)):154-162 https://doi. org/10.1111/ocr.12296

Premkumar S (2015) Textbook of Orthodontics. Elsevier publication, India

Prokopec M, Ubelaker DH (2002) Reconstructing the Shape of the Nose According to the Skull. Forensic Sci Commun 4(1) https://go.gale.com/ps/i.do?p= AONE\&sw $=$ w\&issn $=15288005 \& v=2.1 \& i t=r \& i d=G A L E \% 7 C A 137921462 \&$ sid $=$ googleScholar\&linkaccess $=$ abs

Rana T, Khanna R, Tikku T, Sachan K (2012) Relationship of maxilla to cranial base in different facial types-a cephalometric evaluation. J Oral Biol Craniofac Res 2(1):30-35. https://doi.org/10.1016/S2212-4268(12)60008-6

Riolo ML (1974) An Atlas of craniofacial growth: cephalometric standards from the university school growth study. Craniofacial Growth Series. University of Michigan, USA

Sahni D, Sanjeev, Singh G, Jit I, Singh P (2008) Facial Soft Tissue Thickness in Northwest Indian Adults. Forensic Sci Int 176(2-3):137-146. https://doi.org/ 10.1016/j.forsciint.2007.07.012

Saini V, Mehta M, Saini R, Shamal SN, Singh TB, Tripathi SK (2017) Is North Indian population changing it craniofacial form? A study of secular trends in craniometric indices and its relation to sex and ancestry estimation. Forensic Sci Criminol 2(2) https://doi.org/10.15761/FSC.1000115

Sarode GS, Sarode SC, Choudhary S, Patil S, Anand R, Vyas H (2017) Dental records of forensic odontological importance: maintenance pattern among dental practitioners of Pune City. J Forensic Dent Sci 9(1):48. https://doi.org/10. 4103/jfo.jfds_1_16

Singh G (2007) Textbook of Orthodontics, 2nd edn. Jaypee, India

Stephan CN, Henneberg M, Sampson W (2003) Predicting nose projection and pronasale position in facial approximation: a test of published methods and proposal of new guidelines. Am J Phys Anthropol 122(3):240-250. https:// doi.org/10.1002/ajpa.10300

Taylor KT (2000) Forensic art and illustration, 1st edn. CRC Press, United States

Teja MV, Teja TS (2013) Anthropology and its relation to orthodontics: Part 2. APOS Trends Orthod 3(2):45-48. https://doi.org/10.4103/2321-1407.114149

Umale W, Singh K, Azam A, Bhardwaj M, Kulshrestha R (2017) Evaluation of nasal proportions in adults with class $i$ and class ii skeletal patterns: a cephalometric study. J Orthod Sci 6(2):41-46. https://doi.org/10.4103/2278-0203.205453

Ungar PS, Sorrentino J, Rose JC (2012) Evolution of human teeth and jaws: implications for dentistry and orthodontics. Evol Anthropol 21(3):94-95. https:// doi.org/10.1002/evan.21313

Verma SK, Maheshwari S, Gautam SN, Prabhat K, Kumar S (2012) Natural head position: key position for radiographic and photographic analysis and research of craniofacial complex. J Oral Biol Craniofac Res 2(1):46-49. https:// doi.org/10.1016/S2212-4268(12)60011-6

Wilkinson C (2010) Facial reconstruction - anatomical art or artistic anatomy? J Anat 216(2):235-250. https://doi.org/10.1111/j.1469-7580.2009.01182.x

Windhager S, Mitteroecker P, Rupić I, Lauc T, Polašek O, Schaefer K (2019) Facial aging trajectories: a common shape pattern in male and female faces is disrupted after menopause. Am J Phys Anthropol 169(4):678-688. https:// doi.org/10.1002/ajpa.23878

\section{Publisher's Note}

Springer Nature remains neutral with regard to jurisdictional claims in published maps and institutional affiliations. 